\title{
Trançado: recursos computacionais aplicados no processo de projeto de mobiliário urbano permanente
}

Trançado: computational design thinking applied to a permanent urban furniture project

\author{
Dyego Digiandomenico \\ Universidade de São Paulo, Brasil \\ dyego.sd@gmail.com \\ Gabriele Landim \\ Universidade de São Paulo, Brasil \\ gabriele.landim@gmail.com
}

\author{
Henrique Fischer \\ Universidade de Buenos Aires, Argentina \\ arq.fischer@gmail.com
}

\begin{abstract}
This paper presents and discusses the research, design and construction of the urban furniture "Trançado", permanently located at Largo da Batata, a public space in São Paulo, Brazil. The project was accomplished using computational design processes as parametric modeling and digital fabrication of prototypes. Stakeholders from different areas were involved: professionals, organizations and citizens. The article contributes discussing and describing the technical features. Above all, it produces inputs for reflection and progress of the application of computational design in architecture.
\end{abstract}

Keywords: Urban furniture; computational design; parametric modeling; algorithmic architecture; collaborative processes.

\section{Introdução}

O estado atual da arquitetura é certamente resultado de um processo bastante longo e complexo. As transformações de paradigma no processo de projeto de arquitetura é fruto de pesquisas desenvolvidas nas últimas décadas e intrincadas relações entre tecnologias da informação, comunicação, computação, manufaturas, interfaces, conectividade e outros processos.

A fim de integrar o processo de projeto e os recursos computacionais que atualmente fazem parte das investigações das práticas de design contemporâneos, o presente estudo descreve o sistema de modelagem paramétrica, a prototipagem rápida de modelo em escala como processo auxiliar de projeto e os problemas reais encontrados durante o processo de concepção, fabricação e instalação do mobiliário urbano "Trançado" no Largo da Batata, na cidade de São Paulo, selecionado através do concurso Batatalab.

O projeto do mobiliário foi proposto ao concurso por três arquitetos pesquisadores que formam o Quasares, um coletivo de pesquisa autônomo, formado através da reunião de pessoas com interesses que convergem em tecnologia computacional nos processos de projeto.

O método utilizado na concepção do projeto pode ser chamado de design computacional ou Computacional Design Thinking (Oxman, 2006; Castellano, 2010; Oxman and Gu, 2015) e seu potencial está direcionado em prover soluções mais completas e otimizar variáveis de maneira holística.

Dentro dos níveis de design computacional, está a modelagem paramétrica, utilizada neste projeto, onde em vez de descrever o resultado da modelagem final, descreve-se o processo de modelagem em si. O método, escrito através da programação visual, é constituído por uma sequência de instruções - algoritmos - que geram um modelo com base em um conjunto de parâmetros de entrada.

Embora muito utilizada nos últimos anos, principalmente em pesquisas acadêmicas em todo o mundo, a modelagem paramétrica ainda não faz parte da prática de projeto da grande maioria dos arquitetos brasileiros, apresentando ainda grande campo de discussão não explorado na aplicação de recursos computacionais em projeto.

A contribuição desta pesquisa é a de relatar e discutir a qualidade do processo em vez de apenas analisar o resultado final do projeto, e assim, produzir insumos para a reflexão e avanço da aplicação destes recursos na área.

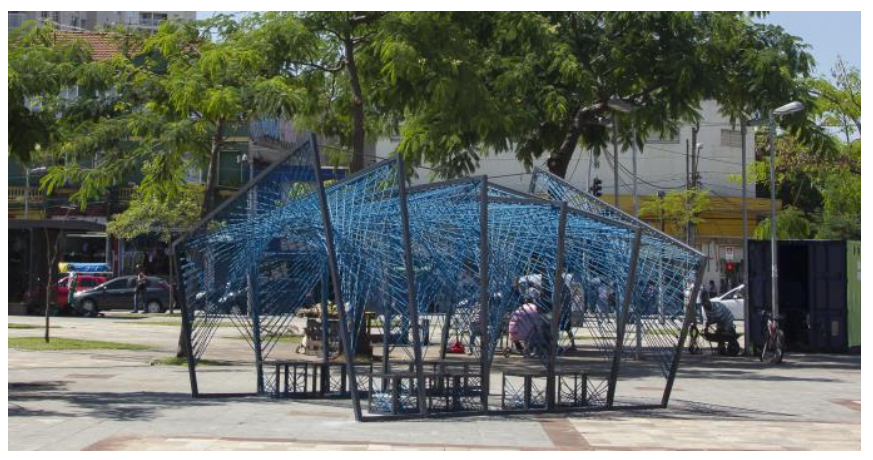

Figura 1: foto do mobiliário Trançado. Fonte: autores. Foto: Rogério Canella 


\section{Background}

Durante mais de dez anos, o Largo da Batata e região passaram por intensas intervenções urbanísticas decorrentes da "Operação Urbana Consorciada Faria Lima", que segundo a descrição oficial tinha por objetivo principal reorganizar os fluxos de trafego particular e coletivo ao implantar o prolongamento da avenida Faria Lima. No entanto após a finalização das obras públicas em 2013, o Largo da Batata, que antes era um lugar ativo e rico em atividades comerciais formais e informais, passou a ser um grande vazio pavimentado e espaço de passagem. Os moradores do entorno e frequentadores da região, então passaram a questionar o projeto final e seu real caráter enquanto praça pública por não conter mobiliário, vegetação e instalações que possibilitassem a convivência e permanência dos frequentadores e transeuntes.

Durante os últimos anos, iniciativas civis de discussão do uso da praça reuniram pessoas interessadas na ativação deste espaço, que se organizaram e iniciaram intervenções de apropriação. Uma destas iniciativas resultou no concurso Batatalab. Segundo o instituto organizador, A Cidade Precisa de Você (2015), o tema do concurso "Sombra", foi definido a partir de uma pesquisa de dois meses com os frequentadores do Largo sobre o que mais desejavam no local, tendo como solicitações principais a necessidade de lugares para sentar e recostar, áreas arborizadas e sombreadas e equipamentos infantis.

Assim, o projeto Trançado foi inserido como parte de uma iniciativa de ocupação e apropriação do espaço público do Largo da Batata, iniciativa sem fins lucrativos, promovido pelo concurso Batatalab, realizado pelos institutos $A$ Cidade Precisa de Você e IPIU (Instituto de Pesquisa e Inovação em Urbanismo).

É relevante apresentar ao leitor os dois pontos de observação que conduziram o projeto Trançado, pois ao se tratar de uma intervenção no espaço público, é necessária uma visão sistêmica que observe o trabalho continuo iniciado anteriormente à instalação dos mobiliários.

O primeiro ponto importante é compreender o processo de transformação do local e as emergências surgidas a partir dessas transformações. Nesta escala estão envolvidos agentes que dão caráter complexo as transformações urbanas, como as esferas sociais, econômicas e políticas, em um processo já iniciado e que ainda se desenvolve. O segundo ponto é compreender todo o nível anterior somado a uma série de necessidades funcionais, como aspectos técnicos de aprovação do projeto na subprefeitura do bairro, orçamento disponível, prazos de entrega e instalação, técnicas construtivas, e solicitações funcionais do edital do concurso.

Faz parte da discussão deste artigo, compreender e explicitar que o mobiliário não atende então somente seus aspectos técnicos e funcionais, tendo como objetivo final não só a instalação-objeto, mas um projeto que além de cumprir seus aspectos funcionais tenta, em conjunto com os outros mobiliários instalados, contribuir como uma interface na configuração geral do espaço, estimulando o convívio, trocas e debates.

\section{Metodologia}

É necessário iniciar a descrição citando os objetivos do concurso que orientaram a concepção, pois por estarem presentes no mobiliário, embasam a compreensão da leitura do projeto enquanto experimento de metodologias e práticas na aplicação do design computacional, e seus objetivos finais enquanto interface, são eles: a. fortalecer e dar suporte a um laboratório de inovação em mobiliário urbano, no Largo da Batata, que sirva como território de testes para inspirar a melhoria de outros espaços públicos; b. promover a pesquisa de novas tecnologias e aplicações na construção, tais como em estruturas, revestimentos, sistema de implantação e o seu desenvolvimento em uma concepção arquitetônica e estrutural apropriada; c. promover a pesquisa de materiais e componentes construtivos e seu potencial de replicabilidade em mobiliários urbanos de praças, parques e calçadas ( $A$ Cidade Precisa de Você; IPIU, 2015).

A partir dos objetivos elencados a equipe constituiu o projeto do mobiliário através da abordagem de pesquisa exploratória, realizando um planejamento para identificar, delimitar e incorporar os critérios que atuavam em cada uma das etapas do processo de projeto, que considerou também a expertise de membros dos institutos e poder público. Foram utilizados recursos computacionais, que viabilizaram a utilização do pensamento algorítmico durante a construção das etapas e suas relações com todo o processo e a parametrização na manipulação das variáveis, formalizadas através da programação visual no editor gráfico de algoritmos Grasshopper no programa Rhinoceros.

Os métodos apresentados a seguir abordam desde o processo de concepção até a materialização e instalação do mobiliário em escala real, entregue como um mobiliário permanente ao espaço público na cidade de São Paulo. É possível delimitar as seguintes etapas de descrição do processo de projeto: concepção, desenvolvimento, revisão (feedback), execução e instalação.

A concepção do projeto se embasou nos objetivos do concurso e em questões funcionais de uso e instalação característicos do próprio local de implantação, sem deixar de equalizar a viabilidade financeira da proposta. Enquanto no desenvolvimento é considerada a modelagem paramétrica do objeto até as simulações de insolação, estas duas etapas são anteriores a submissão do projeto no concurso, durando aproximadamente um mês.

Após a seleção da proposta pelo júri houve uma revisão de acordo com novas informações que surgiram de um maior contato com os usuários da praça e com o retorno do próprio instituto. A partir desse ponto o projeto evoluiu para a etapa de execução gerando a documentação necessária para a aprovação dos órgãos competentes, orçamentos detalhados, fabricação e montagem. Do resultado do concurso até a 
instalação do mobiliário, as fases descritas foram executadas em aproximadamente quarenta e cinco dias.

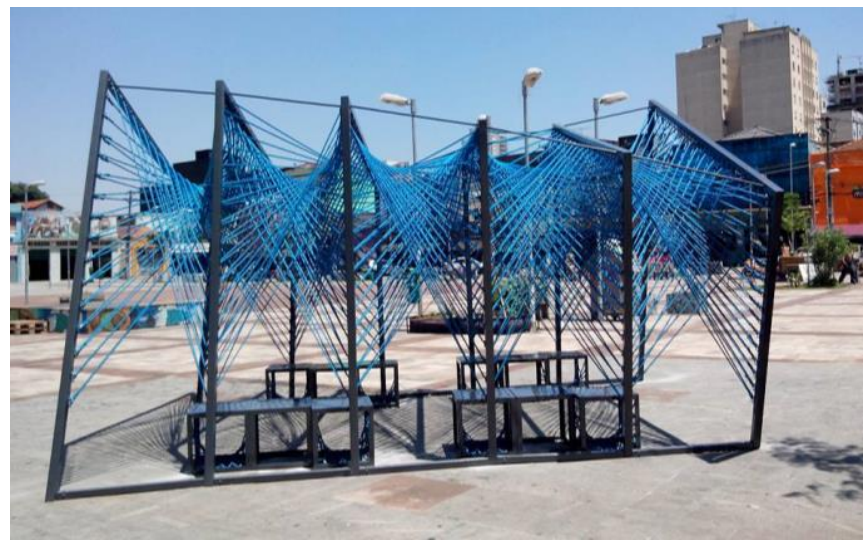

Figura 2: foto do mobiliário Trançado. Fonte: autores. Foto: Nayara Benatti

\section{Resultados}

\section{Concepção}

Entre os principais critérios que o processo de projeto levou em conta na sua concepção, com o amparo dos recursos computacionais, estão:

a. as condições climáticas e relação com entorno: privilegiar a permeabilidade com aberturas e eixos visuais na mesma medida que proporciona sombra e conforto ambiental ao usuário;

b. a função do mobiliário e a apropriação dos usuários: reforçar a intenção do mobiliário em ser confortável para o encontro e permanência, ao mesmo tempo que possui elementos que despertam a curiosidade e o caráter lúdico da instalação, explora a complexidade formal do trançado que o recobre;

c. soluções estruturais: compor através de encaixes simples e componentes leves um sistema estrutural harmônico com o design do projeto e que seja capaz de resistir as cargas, esforços e intemperes no espaço público;

d. material e acabamento: garantir a durabilidade do mobiliário e propor o uso de materiais mais leves que não são comumente utilizados em mobiliários públicos;

e. viabilidade econômica e de fabricação: todas as questões conceituais, funcionais e técnicas devem ser contempladas dentro de um orçamento limitado, definido pelo edital do concurso.

A partir do atrelamento dos parâmetros levantados pela equipe com a capacidade dos recursos computacionais, foi possível explorar a complexidade formal do mobiliário, incorporando aspectos que pudessem transcender o caráter funcional e conferissem o aspecto de experiência aos usuários do local. É nesse sentido de interface que o ciberneticista Klaus Krippendorff sugere a importância das motivações "intrínsecas" no design, que vão além das motivações "extrínsecas", citadas pelo autor como os aspectos funcionalistas de um projeto, que são inseridos para justificar diretamente os resultados finais do objeto. As motivações intrínsecas são justificadas pelo autor como: "as experiências ótimas, o prazer de estar, a satisfação no trabalho, o desfrutar, a emoção e diversão, são intrinsecamente motivadores e são importantes forças motrizes da tecnologia, embora não reconhecíveis por métodos empíricos que celebram o extrínseco e destituem a motivação intrínseca." (Krippendorff, 2004, p.11).

\section{Desenvolvimento}

O projeto foi desenvolvido remotamente entre a equipe, separada entre as cidades de São Paulo e Buenos Aires. Para isso, foi necessário estabelecer a linguagem de compartilhamento e colaboração do modelo paramétrico. Foram utilizados os conceitos de organização em programação modular definidos por Daniel Davis, Jane e Mark Burry (2011), todas as ações do algoritmo foram organizadas contendo: títulos, entradas, saídas, grupo e descrição. Embora trabalhar com o agrupamento dos nós seja uma tarefa simples, estes autores afirmam que esse esquema "pode aumentar significativamente a legibilidade de um modelo, 0 que torna mais fácil seu compartilhamento de forma colaborativa" (Davis; Burry; Burry, 2011, p.66).

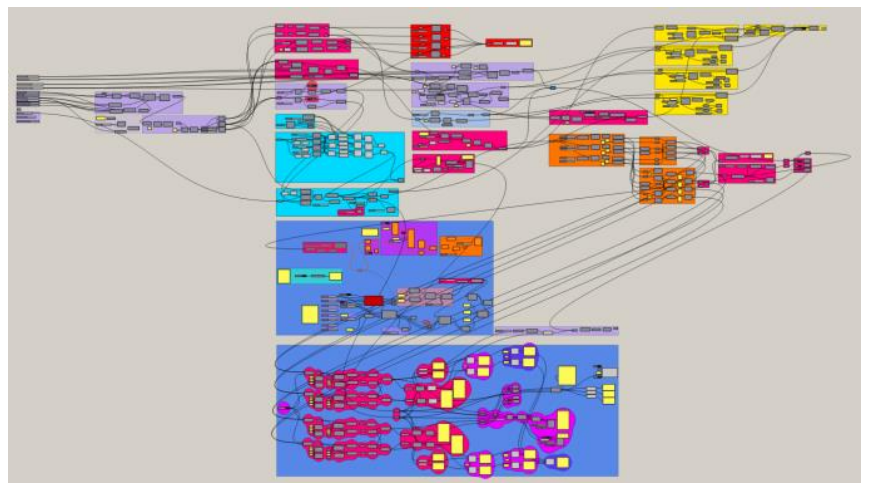

Figura 3: programação visual do projeto final com o plug-in Grasshopper. Fonte: autores.

As principais características técnico-construtivas e as relações subjetivas citadas, foram interpretadas pelos arquitetos e declaradas em um encadeamento de parâmetros através da programação visual. Os cruzamentos desses parâmetros deram luz as primeiras investigações e testes de desempenho da forma inicial.

As variáveis, conforme eram inseridas e consideradas no projeto, interferiam diretamente na forma, porém mantinham relações de negociação e balanceamento estipuladas pelos arquitetos através dos algoritmos, para que todo o resultado fosse reflexo das necessidades informadas. Este é um conceito básico presente na parametrização, onde se estabelece as relações pelas quais as partes se conectam, permitindo que o sistema projetado se encarregue de manter as concepções consistentes com as relações, possibilitando princípios de "automação" no projeto (Woodbury, 2010, p.24). 
Um exemplo claro dessa relação entre os elementos listados anteriormente, foi a inserção dos parâmetros que configuraram o posicionamento e complexidade do trançado das cordas na cobertura e a relação de rotação entre os pórticos estruturais, um cruzamento de quatro variáveis: os padrões extraídos da pesquisa dos arquitetos com tipos de trançados brasileiros; a posição e distribuição do encordoamento em relação aos índices de incidência solar simulados computacionalmente; a quantidade e diâmetro do material de encordoamento; o desempenho estrutural simulado do posicionamento dos pórticos verticais em relação as dimensões gerais do mobiliário e as cargas decorrentes da própria estrutura e da quantidade de cordas.

\section{Revisão}

Após o anúncio do projeto selecionado pelo júri do concurso, ao longo do desenvolvimento do projeto executivo, a equipe passou a estabelecer contato com os membros dos institutos e membros do movimento civil que atua na região.

O design computacional possibilitou nesta fase, um retorno de informações obtidas ao longo das conversas e feedbacks entre os envolvidos. As mudanças e aprimoramentos do projeto puderam ser inseridos como variáveis modificadas, assim, as simulações eram facilmente recalculadas e as novas relações que ainda não estavam declaradas, poderiam ser inseridas no algoritmo, aproveitando os dados e relações existentes.

Este processo de revisão é natural no processo de projeto, pois nas etapas iniciais das propostas, é comum que os problemas de concepção não possam ser formulados de forma abrangente (Lawson, 2005). Porém, no método tradicional de projeto, a viabilidade destas transformações seria muito trabalhosa e praticamente impossível devido à complexidade formal do mobiliário, o encadeamento de parâmetros e os prazos do concurso.

Como exemplos de dados que passaram a informar o projeto após o contato das equipes, podemos citar: posicionamento e implantação, que resultaram em ajustes no posicionamento e quantidade de pórticos verticais; cores e acabamentos dos materiais e fixação e montagem.

\section{Uso das Tecnologias de Prototipagem Rápida e Fabricação Digital}

O uso da modelagem paramétrica na concepção de projeto fornece dados e geometrias que podem ser materializadas de maneira direta, rápida e automatizada com a fabricação digital dos modelos em escala.

Essa fase se torna fundamental durante o processo de projeto, pois permite ao projetista observar o modelo em escala e elucidar uma série de problemáticas das fases de concepção e desenvolvimento que não eram possíveis de serem identificadas com facilidade no modelo digital.

No desenvolvimento do projeto, os usos da prototipagem rápida com fabricação digital aconteceram em dois momentos.
O primeiro foi a produção do modelo em escala 1:9, utilizando a máquina de corte a laser em madeira MDF $3 \mathrm{~mm}$. Por se tratar de uma tecnologia de corte 2D, foi adicionado ao algoritmo a planificação das peças estruturais e a disposição na placa para o corte. Foram produzidos simultaneamente dois modelos em escala, um em cada cidade, para que a equipe pudesse continuar 0 desenvolvimento em consonância. Esta fase foi fundamental à viabilidade da construção real, pois foi possível prever aspectos da fixação e ordem de montagem do projeto final.

Foi identificada a necessidade de inversão da ordem das camadas do trançado. No modelo em escala, a ordem de trançado prevista inicialmente era adequada, pois era trançada por quem via o modelo de cima, porém para montagem in loco seria necessário começar da camada de cordas que alcançariam o ponto mais alto da estrutura. Foram realizados ajustes na ordem das listas de dados, a fim de viabilizar a construção real.

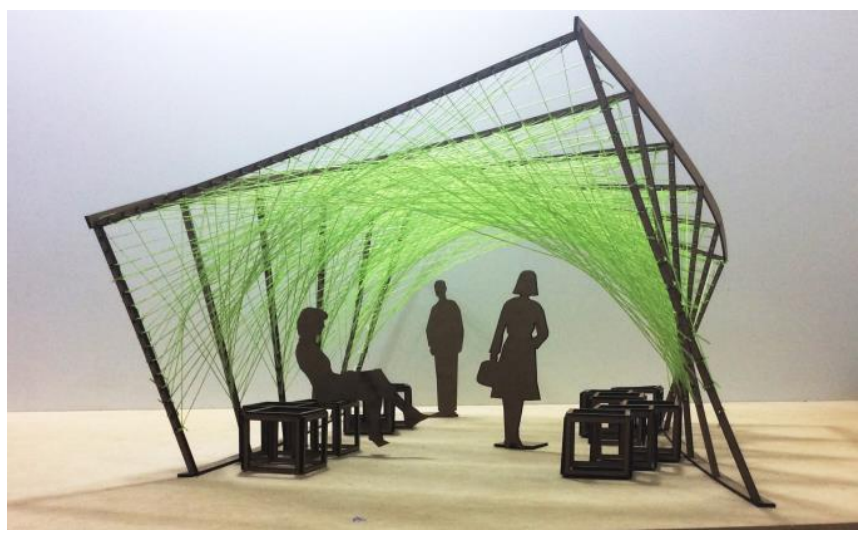

Figura 4: modelo em escala 1:9 produzido com máquina de corte a laser. Fonte: autores.

O segundo momento de aplicação da fabricação digital foi na prototipagem de trechos da estrutura em escala real, utilizando impressão 3D para o estudo e viabilidade da fixação do encordoamento e montagem dos pórticos estruturais. A prototipagem deu subsídios para a tentativa de viabilizar a produção final da estrutura do mobiliário com fabricação digital, com corte a plasma das chapas e seus respectivos furos de fixação do encordoamento, e formação das partes da estrutura com as chapas dobradas em dobradeiras CNC. No entanto, com a análise de todos os parâmetros obtidos até esta fase, foi identificado que a fabricação do mobiliário através de fabricação digital não seria viável financeiramente, e os prazos seriam incompatíveis com os adotados pelas indústrias que poderiam prestar esse serviço. 


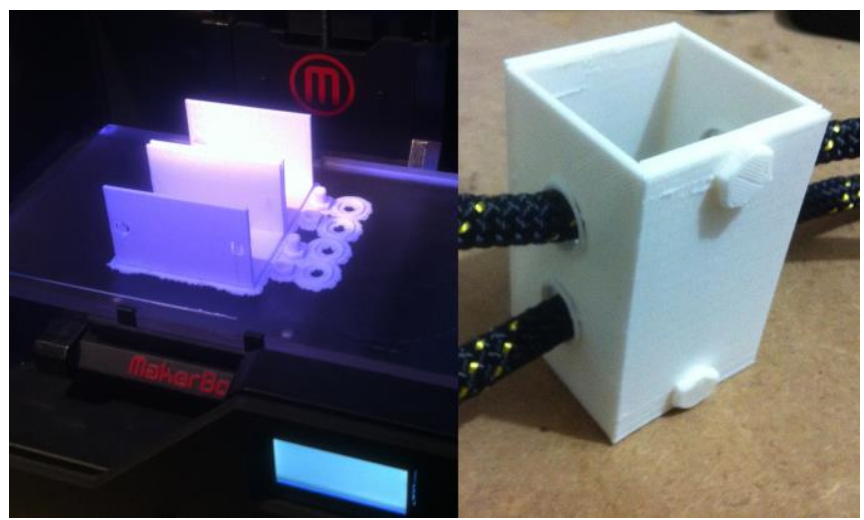

Figura 5: protótipo em escala 1:1 produzido por impressão 3D. Fonte: autores.

Sendo assim, foram reinseridos parâmetros no modelo a fim de readequá-lo para a fabricação com perfis comerciais préfabricados e a mudança da fixação do encordoamento através de argolas metálicas fabricadas pela serralheria.

Os cálculos estruturais de desempenho dos novos perfis foram refeitos e o projeto passou da fase de finalização para o início da fabricação e montagem.

\section{Execução e Instalação}

Para dar início à fabricação e montagem do projeto pelo serralheiro, foi necessário gerar a documentação tradicional de arquitetura, indicando os ângulos e cortes necessários para a fabricação, assim como passo a passo da montagem, soldas e fixações.

Também foi dedicado muito tempo de supervisão à fabricação das peças, uma vez que o trabalho foi manual e utilizava técnicas simples para medição de ângulos (transferidor), cortes e identificação manual das peças.

A partir dos recursos computacionais utilizados na concepção e desenvolvimento do projeto, foi possível viabilizar um trançado complexo a partir da extração e organização dos dados. A lógica de posicionamento do encordoamento projetado está intrinsecamente ligada aos fatores estruturais, ao posicionamento geral da estrutura, aos fatores de incidência solar, aos parâmetros extraídos de técnicas de trançados brasileiros e a especificação técnica do material das cordas. Ou seja, todo o projeto mantém relação entre suas variáveis, não sendo possível desassociar a geração da forma de seus parâmetros.

A extração dos dados para a execução do encordoamento foi prevista no algoritmo e realizada a partir das observações obtidas na construção do modelo em escala. Foram estabelecidas quatro camadas de trançado que se sobrepõe. $O$ documento gerado para esta ordem foi uma planilha que identificou passo a passo a ordem do trançado e pontos de fixação.

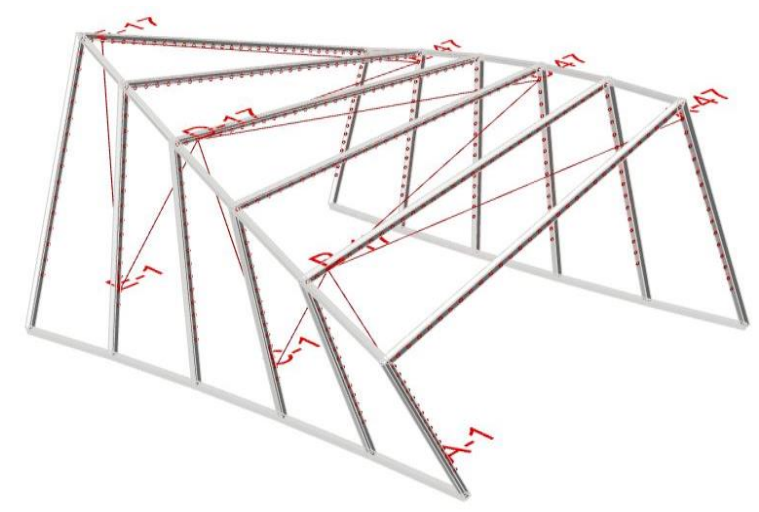

Figura 6: modelo digital que contém os dados de posicionamento e ordem de trançado das cordas. Fonte: autores.

Além disso, os dados de quantificação dos materiais foram extraídos e sistematizados através do algoritmo, priorizando 0 consumo consciente e não desperdício de materiais.

A estrutura do projeto é composta por seis pórticos metálicos verticais, posicionados paralelamente uns aos outros, fixados com travamentos superiores em barra de ferro redondo e travamentos inferiores em barras metálicas de seção quadrada. Ao longo de cada pórtico, estão posicionadas argolas metálicas, que orientam o trançado das cordas de polietileno.

Ao todo, foi necessário um dia para a instalação e montagem da estrutura, que contou com equipe técnica especializada e três dias para a execução do trançado, que contou com o trabalho voluntário de maneira colaborativa dos autores, pesquisadores e sociedade civil.

\section{Discussão}

A produção e instalação do mobiliário Trançado contribui para, de um lado, a aplicação, reflexão e validação real sobre o projeto de arquitetura feito a partir de recursos computacionais, modelagem paramétrica e fabricação digital, e de outro, contribui no caráter de laboratório proposto pelos coletivos e sociedade civil organizada que atuam no Largo da Batata, gerando dados de uso do espaço e insumos de pesquisa para a discussão sobre o uso e apropriação do espaço público.

Este projeto ainda fomenta e incentiva a discussão sobre a aplicação e manutenção de materiais que não são tão comumente usados em mobiliários urbanos e a importância da variabilidade de propostas de design na exploração de aspectos funcionais e estéticos dos mobiliários atualmente implantados na cidade. 


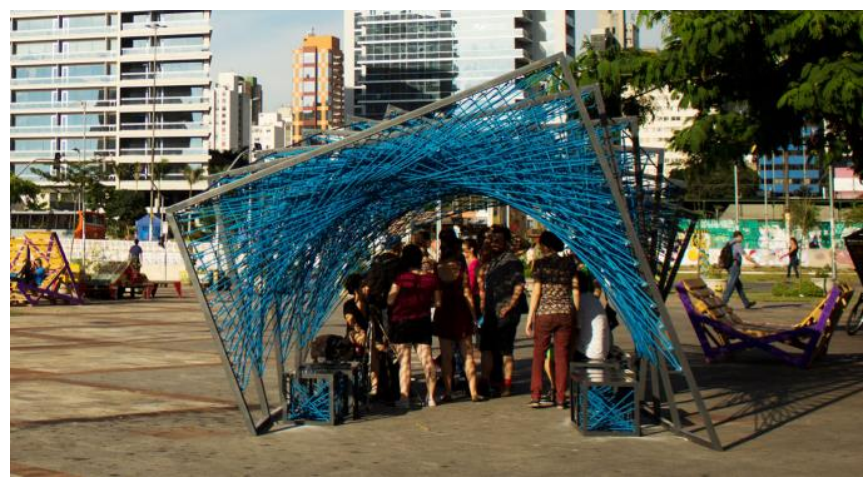

Figura 7: foto do mobiliário Trançado ocupado. Fonte: autores. Foto: Thiago Miagy.

\section{Considerações Finais}

Alguns aspectos da relevância do uso de recursos computacionais no processo de projeto ficam evidentes: o potencial da parametrização na concepção facilitou revisões e evoluções do processo, demonstrando aspectos positivos em abranger a pesquisa coletiva e inserção de dados que estimulam a integração do contexto físico e cultural do local.

Quanto à fase de concepção e desenvolvimento, a Fabricação Digital mostrou-se facilitadora para materialização de modelos, o que possibilita o teste do projeto e torna seus problemas mais visíveis. Deste modo, a equipe teve amparo em visualizar problemas que dificilmente poderiam ser identificadas sem o uso dessas tecnologias, o que levou a um refinamento e qualificação do processo de projeto. Além disso, a construção do modelo com fabricação digital possibilitou que pudessem ser produzidos protótipos em ambas as cidades, com a rapidez necessária para que a produção pudesse ser viabilizada dentro dos prazos.

As vantagens de desenvolver o projeto através de algoritmo, entre muitos aspectos, é ter o modelo disponível inteiramente em dados, viabilizando assim o sistema file-to-factory (do arquivo para a fábrica) que é caracterizado pela comunicação direta entre 0 arquivo digital e o equipamento de produção controlado numericamente utilizado para a fabricação do projeto (Pupo, 2009, p.103). Esse processo interfere na maneira como o arquiteto documenta o projeto, eliminando a necessidade de documentação padrão encontrada na indústria da construção civil, como plantas, cortes e elevações.

Embora em ascensão e conhecidas pela facilidade de customização da produção, as práticas de fabricação digital aplicada à arquitetura em São Paulo ainda são restritas. Não foi possível encaixar no orçamento disponível os valores estimados para a fabricação usando estas técnicas.

Outro fator crucial para a mudança de estratégia de fabricação foi a inviabilidade do tempo de resposta do orçamento, dificultado pela exigência da indústria em realizá-lo apenas com a documentação tradicional das peças, além da pouca receptividade em colocar na linha de produção a fabricação de uma única unidade de um projeto, demostrando pouco alinhamento da indústria com preceitos de fabricação digital.

Contudo, a concepção, fabricação e instalação do mobiliário demostrou receptividade por parte dos organizadores do concurso, subprefeitura e usuários, ascendendo a discussão sobre a relevância do design também enquanto experiência a partir da estética que pode ser explorada com o uso de recursos computacionais sem desconsiderar fatores funcionais.

\section{Referências Bibliográficas}

A Cidade Precisa de Você. (2015). Batatalab: concurso de mobiliário urbano no Largo da Batata. Retrieved from http://www.acidadeprecisa.org/\#!projeto-01/pkugu

A Cidade Precisa de Você, IPIU. (2015). Edital: chamada pública de projetos para o concurso Batatalab.

Castellano, D. (2011). Humanizing Parametricism. In Procedings ACADIA Regional 2011: Parametricism. p275- 279.

Davis, D., Burry, J., \& Burry, M. (2011). Untangling Parametric Schemata: Enhancing Collaboration through Modular Programming. In CAAD Futures 201: Designing Together, p. 5568

Krippendorff, K. (2004). Intrinsic Motivation and Human-Centered Design. Theoretical Issues in Ergonomic Science, 5 (1), p.43-72. Retrieved from http://dx.doi.org/10.1080/1463922031000086717

Lawson, B. (2005). How Designers Think: The Design Process De-mystified, Elsevier/Architectural Press, Amsterdam.

Oxman, R., Gu, N. (2015). Theories and Models of Parametric Design Thinking. In ECAAEE 2015 Vienna, Austria. p1-5.

Oxman, R. (2006) Theory and Design in the First Digital Age. Design Studies, Vol. 27 No. 3 pp. $229-265$.

Pupo, R. (2009). Inserção da prototipagem e fabricação digitais no processo de projeto: um novo desafio para o ensino de arquitetura. Campinas, 240p. Tese de doutorado. FEC UNICAMP.

Woodbury, R. (2010) Elements of parametric design. Oxford: Routledge 